\title{
Network Usage Tariff (NUT) structure and vision in Hungary in consideration of renewable generation trends
}

\author{
Dr. I. Vokony ${ }^{1}$ IEEE \\ ${ }^{1}$ Department of Electric Power Engineering \\ Budapest University of Technology and Economics \\ Muegyetem rkp. 3. Budapest 1111 (Hungary) \\ Phone/Fax number: 00361 463-3030, e-mail: vokony.istvan@vet.bme.hu
}

\begin{abstract}
The consumption behaviour focus points are changing nowadays: in certain areas start industrial developments where entirely different needs were common, creation the new consumer design of multi-directional connections generate pressure to loosen regulations; climate change is changing malfunctions impact; widespread use of renewable energy sources; etc. Beyond the global trends there are huge facilitators in Hungary which can basically act to regulation, pay-off and supplying methods. In the paper one really important and sensitive cost element will be investigated - the Network Usage Tariff (NUT) - and its influential elements: governmental overhead reduction, increasing renewable penetration, changing subsidy systems.

After introducing the existing business case and the possible trends, affecting regulation and market changes, the scenarios will be analysed and results summarized. At the end as an outcome a proposal will be presented.
\end{abstract}

\section{Key words}

Network Usage Tariff (NUT), Regulation, Renewable Energy, Subsidy Systems

\section{Introduction}

We look beyond immediate priorities to identify the challenges Europe's energy markets will face in the coming ten years in order to inform the energy regulation agenda. A dialogue shall continue to engage with all energy actors, including consumers, stakeholders and European Institutions, to meet future challenges and take necessary and appropriate action.

The full implementation of European energy legislation, including the electricity and gas Network Codes and the application of Target Models, to achieve liquid, interconnected electricity and gas markets, and consumer rights, energy efficiency and market integrity measures, will continue to be our central priority.

The energy sector is embarking on a profound period of change - in how we produce, consume and transport energy - designed to promote a more sustainable and efficient energy sector. In the upcoming 10-15 years will see Europe moving to a low carbon society with increased renewable energy and smart responsive energy supply. Very real changes will emerge in the way consumers engage with the market and much greater and active involvement of smaller consumers in the energy (principally electricity) market will be needed. An anticipate major increase in generation will be from renewable sources which will give rise to a much greater need for flexible reserves from other sorts of generating plants and from the demand side itself.

Changes in technology (smart grids, smart meters) will enable, and empower, smaller consumers to help provide this flexible response. New services will help consumers to manage their energy needs more effectively.

\section{NUT basics and trends}

The composition of network usage tariff (NUT) in Hungary is defined by the HEPURA (Hungarian Energy and Public Utility Regulatory Authority) regulation 4/2013. (X. 16.). The fee paid by the distribution licensees to the power company covers the network operational costs. The regulation specifies the system usage fees as follows (Fig1.):

Distribution base fee: Annual fee which is stated on the invoice and has to be paid monthly in 12 equal instalments and per connection point. The fee covers the operational, physical loss and control costs of high voltage transmission network.

Distribution performance fee: The payment takes place based on the highest fixed performance specified by the user in contract. The period of performance contracting is one year; ergo the fee is also defined to a one-year period and has to be paid monthly in 12 equal installations.

Distribution turnover fee: Covers the costs in connection with the operation and maintenance of distribution network and ensuring the continuity of the service.

Distribution reactive power fee: Is applied for the settlement of the inductive or capacitive reactive power. In case of lacking the measurement of reactive power the item has to be defined with $\cos (\varphi)$ value 0.9 .

Distribution loss charge: Electricity supply has loss according to the laws of physics, therefore the power plants have to manufacture more than the amount of energy actually received by the users. The difference is the network loss which each user has to pay in proportion to the used amount of energy. 
Distribution schedule balancing fee: In case of changes in consumption because of weather or other deviation from schedule, the system operator maintains balance between the consumption and the manufacturing. The fee covers this process.

\section{NUT $=$ base fee + load fee + energy consumption-based fee}

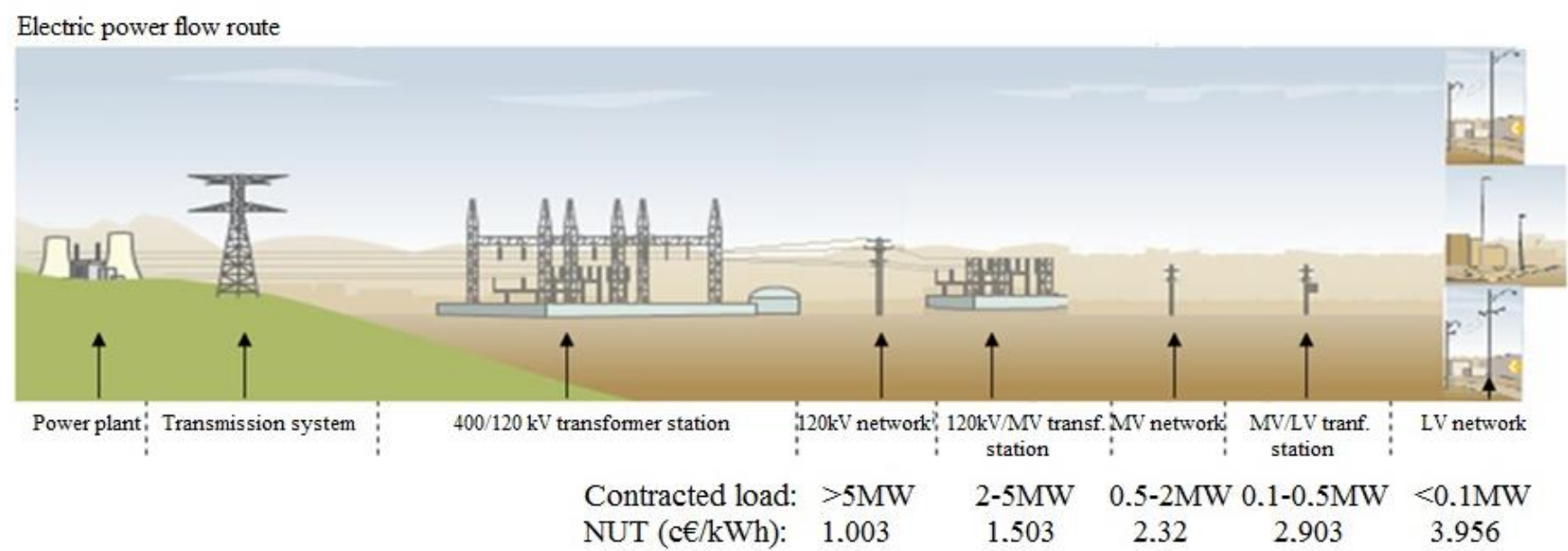

Fig. 1. Electric power flow route, tipical load limits and NUT prices in Hungary

\section{Structure and elements of prices}

The (original) Hungarian energy policy objectives are the:

- Low energy prices for industry (the economy), international/global competitiveness

- A single regional and European energy markets

- European product prices equalizing, targeting, helping industries in the EU competition among each other

- The free movement of goods and services by increasing consumer choice.

Meanwhile, the high European gas prices and the economic crisis afflicting consumers perceived impact on domestic consumer prices was the political factor, which changed the priorities in some countries:

- of effective competition hit shot fell,

- real or artificial voiced -the risk of security of supply,

- reducing effects of regulated prices for consumers (rather than competition) as a tool of crisis.

The impact of policy interventions on the electricity consumer price developments in the components: the relative proportion of the energy component of consumer prices decreased in the smallest increase in product prices, while the highest in taxes and various support elements. Since 2008 the network fees increased by $18.5 \%$ in households and $30 \%$ for industrial consumers. Taxes and support items rose by $36 \%$ to domestic customers and $127 \%$ in the industrial ones.

The tax and industrial policy objectives, effects of market interventions smote results!

In the meanwhile the Hungarian energy, universal service prices are even lower because of the governmental overhead reduction and other aspects. The prices structure can be seen in Fig2. and Fig3. in absolute value and percentage as well. The real question is the sustainability of electric energy supply taking into consideration the trends and possible scenarios.
The effects of Climate Change Policy Goals on the market operation, cost elements and prices (Status Review of Renewable and Energy Efficiency Support Schemes in Europe): The survey analysed data of 18 countries. The result shows: Unit support levels on final electricity consumed vary from 0.12 to $20.61 € / \mathrm{MWh}$, while the average support is around $7 € / \mathrm{MWh}$ (2010). The weighted average: $\approx 9 € / \mathrm{MWh}$

The lack of harmonised renewable support schemes hamper the convergence of commodity prices and not support efficient use of resources!

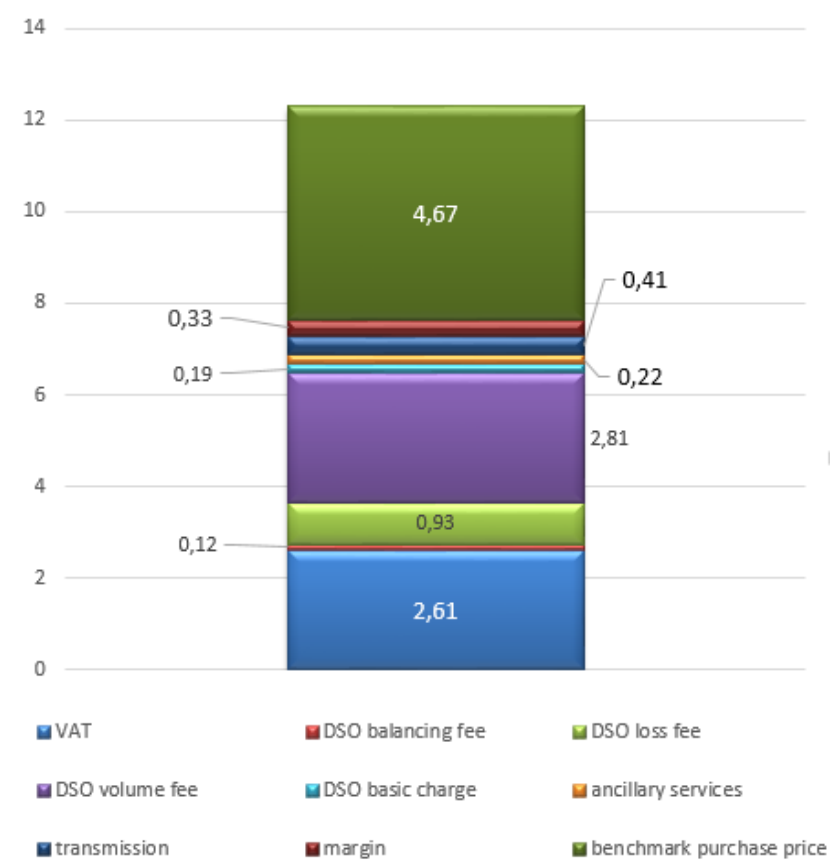

Fig. 2. Universal service prices structure [HUF/kWh] 


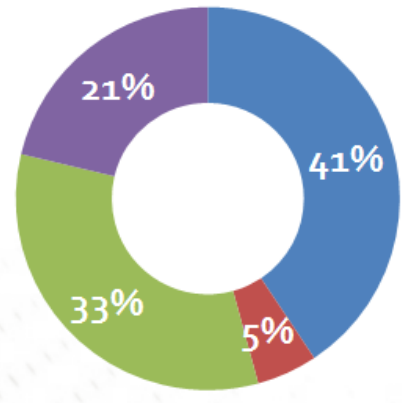

Energy, margin $\square$ Transmission

- Distribution $\quad$ VAT

Fig 3. Universal service price structure

\section{Influences and impacts}

The tariff structure and thereby the NUT suffers from several influences. Furthermore these impacts are not necessary in correlation, and/or the effects are difficult to identify. In the followings the most common and important influences are under review.

\section{A. National energy strategy}

The long-term goals of the National Energy Strategy (of Hungary) and the effects of these on the Hungarian power plant portfolio technical and economic situation are the following:

Increasing energy saving and energy efficiency:

The fastest and easiest way of increasing the security of supply is reducing consumption by increasing energy saving and energy efficiency. The target is that our 1085 PJ primary energy consumption (2010) would increase with maximum 50 PJ until 2030 - considering the effect of the additional objectives. To reach the target, at first, building energy programs are starting. Then it continues with the replacement of outdate power plants and ends with the retirement of low-efficient renewables. The result of the program is the decrease of the primary energy import dependence and the vulnerability towards the neighbouring countries.

Increasing renewable energy manufacturing with low $\mathrm{CO}_{2}$ emission:

The actual $7 \%$ ratio of renewable primary energy consumption is expected to increase to $14.65 \%$ until 2020 due to our 20/20/20 EU-target (it has to equal $20 \%$ in 2030). The National Energy Strategy gives priority to the spectacular types of renewable power generation: to the cogeneration biogas and biomass plants and to the forms of geothermal energy utilization. Utilizing the potential of the photovoltaic plants starts possibly from the early 2020's. The impact of the renewable power plants on the energy prices in the clean-energy market can be seen in market problems and examples of other EU member states. From a long-term perspective, it can lead to similar problems in Hungary, too.

Transport electrification, transport development:

For decreasing the energy dependence of the transport in our country, it is required to change the fuel used. A goal of the National Energy Strategy is that the ratio of the electric and hydrogen-powered vehicles to all vehicles both in the road and railway sector - has to be at least $9 \%$ in 2030. The ratio of biofuel-powered vehicles has to be $14 \%$ in the same year. It is necessary for the transport electrification to build the charging infrastructure and to set the nuclear power plant capacity which is required to fulfil the demand.

Connection to the European energy infrastructure:

The common European electricity system is long ago one of the EU targets. However, after several attempts, it has not been finished yet. For the integration of Central European cable network into the European system it is required to build further cross-border capacities and to create a complete system monitoring institution and a market monitoring institution.

\section{B. Governmental overhead reduction}

As a result of the changes in legislation at the end of 2012, the prices of users supplied by the universal service providers decrease had a 10\% decrease in 2013 compared to the previous year. The modification of HEA (Hungarian Electricity Act), the MND (Ministry of National Development) regulation 78/2012 and the HEPURA resolution 1092/2012 contain the main rules of the reduction.

The modification of HEA took out the framework of mandatory off-take - feed-in-tariff system (FIT) from the obligations of the universal service providers, so only the competitive market segment purchases the renewable energy produced in the FIT system since 2013.

- The MND regulation modifies the prices of the universal service. It defines the highest electricity prices which are applicable by the universal service providers concerning the base fee, the energy fee and other items. The regulation defines the maximum prices differentiated per service provider, as before, and specifies a universal margin level $(0.439 \mathrm{c} € / \mathrm{kWh})$.

- The HEPURA determines the NUT per purchasing categories - low, medium and high voltage users. On one side, the regulation contains the price changes based on the cost review of the new regulatory period. On the other side, it contains the transfer within the NUT between the user categories.

Transfer within network usage tariff (NUT):

In case of the prices of low-voltage connections, there is a significant decrease. The $13 \%$ price reduction of lowvoltage (profiled users) is compensated by the significant price increase of the medium and high voltage users. Because the turnover and the price per unit of consumption in the latter categories are lower than in the low-voltage category, it is required to have a very large increase in medium and high voltage consumption to compensate the low-voltage user price reduction.

From the perspective of the complete NUT price distribution, the significant 63 million $€$ price increase of the large industrial consumers offsets the 76 million $€$ decrease of the small consumers. This means that the $78 \%$ of the costs is transferred to the distinct consumer groups. The remaining 16 million $€$ difference boils down to the service providers. These items are influenced by the official cost review, therefore it is not definable whether the difference is because of the cost reducing regulation only or not.

Moreover, the $\%$ changes marked in the third column of the Table I. below seem outliers from the perspective of 
the NUT fee changes in the previous 10 years, but there were similar price changes in the high voltage category during 2009 and 2010 interestingly. The $36 \%$ price increase in 2009 was followed by $33 \%$ decrease in the next year.

Table I. - Impact of the Hungarian DSO margin increase

\begin{tabular}{|l|c|c|c|c|c|}
\hline & $\begin{array}{c}\text { Margin } \\
\text { in 2012 }\end{array}$ & $\begin{array}{c}\text { Margin } \\
\text { in 2013 }\end{array}$ & & & \\
\hline c€/kWh & c€/kWh & difference & $\begin{array}{c}\text { Proportion } \\
\text { of load } \\
\text { GWh* }\end{array}$ & $\begin{array}{c}\text { Impact of margin } \\
\text { increasing, million } €\end{array}$ \\
\hline EDF DÉMÁSZ Zrt. & 0.570 & 0.439 & 0.132 & 1827.2 & 2.4 \\
\hline E.ON Energy Supplier Kft. & 0.642 & 0.439 & 0.203 & 5852.5 & 11.9 \\
\hline ELMú Nyrt. & 0.620 & 0.439 & 0.181 & 2913.5 & 5.3 \\
\hline ÉMÁSZ Nyrt. & 0.643 & 0.439 & 0.204 & 1658.7 & 3.4 \\
\hline Total & & & & 12251.9 & $\mathbf{2 2 . 9}$ \\
\hline
\end{tabular}

*Calculated flow, based on transaction data from 2011.

Summarizing the changes in connection with NUT, we can tell that the higher volume of charges was solved by transferring to the large consumer group. The service provider has to bear a smaller part of it. (It is possible that the service load calculated contains the effect of the last year's cost review.)

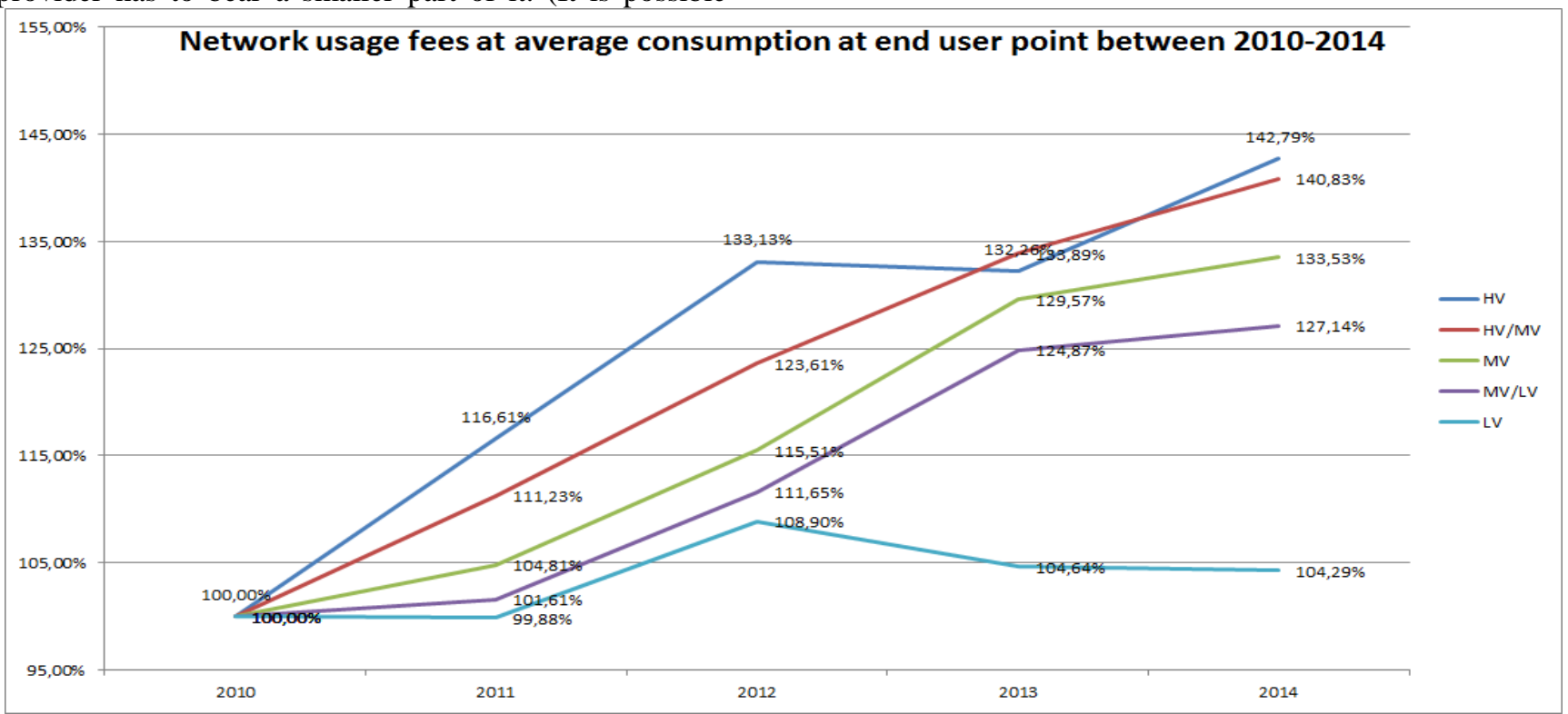

Fig 4. Industrial consumers' NUT fees increased above inflation with $27-42 \%$

\section{Renewable penetration and subsidies}

The regulation was changed on 1 Oct 2016 fundamentally within the issues of price regulation, timed on the start of the new price control period, 1 Jan 2017. The methodology of defining NUT - which contains the accurate price structure for the next 4 years applied by HEPURA and the calculation logic of the new schedule was published on 25 Oct 2016, according to the HEA 178/T. $\S(2)$ b) about temporary rules.

The actual applicable price regulations define the processes of the price control period loaded with threestage cost reductions started in 2013. These processes promote direct price regulation legally, too. At present, the roles are divided between the competent ministry (MND) and the energy regulator (HEPURA) in several issues. In many cases, the regulations and legislations over the last 4 years has overwritten the previously applied professional principles.
The HEA which is applicable from 1 Oct 2016 gives new bases to the sectorial regulation of prices. The regulation of the NUT and connection fee will become the exclusive role of HEPURA. The application of guidelines and fees will appear within a regulation, however, the methodological guidance and the concrete price definition per distributor based on the guide will return. The status before 2012 resets, because the resolutions can be discommended by the stakeholders, while the prices in the regulations cannot.

In the next period, HEPURA will publish many key documents, possibly according to the schedule below:

- $\quad$ Price regulatory framework: 15 Oct 2016 (basic principles, elements of tariff structure, etc.) General methodology guide: 25 Oct 2016 (concerned factors and applied methodology during defining well-founded cost base) 
Methodological guide to the definition of system usage fees: 31 Oct 2016

- $\quad$ Price definition resolutions: 16 Nov 2016

- HEPURA fee application regulation: 16 Nov 2016

Transforming the price regulation is required basically because of EU infringement procedure. On the other side, the regulator is under pressure at present, too. The expectation of EU is to define the prices based on a transparent and professional methodology. However, the governance still has a strong control on the residential end-user prices, because the 2013. LIV. law is still applicable. The law maximized the high limit of the prices applicable from 31 Aug 2014, for an indefinite period. The mentioned limit is $94.3 \%$. The energy unit prices which are applicable within the universal service will be still controlled by the MND regulations. The network licensees can discommend the completed price control resolutions legally, therefore the final price control and the direction of NUT changes is hard to estimate at present. Based on the HEA which is applicable from 1 Oct 2016, the user has to pay the electricity price according to the conditions of the purchasing contract and the system usage fees according to the network usage contract. The definition of official prices concerns only the maximized payment. Deviating from the highest price downwards is possible only if it is published before and if there is no differentiation. In the following period from 2017, NUT and connection fee regulations takes place in 4-year price control periods. The structure which is evolving in the fall of 2016 will define the operational environments of the distributors until the end of 2020.

\section{Conclusions}

The results of the analysis and some conclusions can be formulated:

- Market characteristics determine possible market models - thus price regulation areas

- Long-term contracts and agreements have huge influence on market structure

- Dominant market players and price authorities can distort markets and competition

- Generous support schemes usually works

- Regulated supplier margin is not in line with requested service conditions

- Requested service conditions are not adjusted to customer needs

- Energy poverty is a growing problem but

- Why not to try competition at last (with strict market supervision)?

Regulatory anomalies must be mitigated in order to bring back long-term thinking into the sector!

Furthermore, the proposed consideration:

- Regarding the market opening process some of the end user expectations already met
- Regarding the cost structure the governmental, regulatory playing filed is considerable (LV: $67 \%$ )

- In consideration of wholesale price the difference between European and Hungarian market price level is huge $(6-8 € / \mathrm{MWh})$

- The free-market electricity can be achieved more favorable terms of energy supply, such as universal service for business customers.

- In consideration of subsidies the way of calculating feed-in tariffs need to be reviewed (VET 171§.8-12)

- Regarding the NUT: the growth rate does not exceed the rate of inflation!

\section{Acknowledgement}

This work is connected to the WEC HYPE (Word Energy Council - Hungarian Youth Professional in Energy) activities and regular workshops. Author is a co-founder member and it makes possible to present this paper.

\section{References}

[1] Dr. Grabner Péter - Hungarian Energy And Public Utility Regulatory Authority, The challenges of national energy regulations - Network licensees future roles, MEE VGY, Szeged, Hungary 2016.

[2] Dr. Hartmann Bálint, Sörés Péter, Dr. Divényi Dániel, Farkas Csaba, Kiss József, Analysis of possible DSO services in micro grid systems, Research report Hungarian Electrotechnical Association, Budapest, 2016.

[3] István Vokony, Balázs Bonda, Attila Talamon, Máté Nagy, Gergő Holló, Advancing Opportunities in Renewable Energy Production, YBL Journal of Built Environment, Volume 3, Issue 1-2 (Dec 2015)

[4] Dr. Szörényi Gábor ERRA, The Forecasted European Energy Market Prices in the Key European Energy Markets and Impact of Climate Policy Goals, Budapest, February 2015.

[5] SGTF-EG3 Report, Regulatory Recommendations for the Deployment of Flexibility, EG3 Report Smart Grid Task Force, Brussels, January 2015

[6] ERRA Training Course: Price Regulation and Tariffs, Case study - Retail price regulation in Hungary -, Budapest, Hungary May 11-15. 2015.

[7] ACER, European Gas Target Model Review And Update, January 2015

[8] ACER, Energy Regulation: A Bridge to 2025, 2015

[9] EnergyUK, European electricity network codes, January 2015

[10] ENTSO-E, ENTSO-E overview of Internal Electricity Market -related project work, 13th October 2014

[11] Bobula András, The effectivity of market opening - the FIT and NUT impact on the end-user costs, MESZ XXI. National Conference, Hódmezővásárhely, 13 to 15 October 2014.

[12] Regional Centre for Energy Policy Research Corvinus University of Budapest, Storm in energy overhead - RCEPR analysis about Overhead reduction in Janurary 2013., Budapest 2013.

[13] Almási L., Bonda B., Gerse P., Hartmann B., Hegedűs Z., Holló G., Talamon A., Vágó T., Vokony I, HYPE report $2013-$ Renewables/Energy/Planning/Policy, http://www.wec.hu/wpcontent/uploads/2013/10/WEC_HYPE_report_2013.pdf [online]

[14] stoRE, European Regulatory and Market Framework for Electricity Storage Infrastructure, Deliverable 4.2 - June 2013

[15] IEA (International Energy Agency), Technology Roadmap Smart Grids, 2011 